\title{
Climatic effects and impacts of lakeshore bank designs on the activity of Chirixalus idiootocus in Yilan, Taiwan
}

\author{
Wen-Shang Hou ${ }^{a}$, Yuan-Hsiou Chang ${ }^{a, *}$, Hsiao-Wen Wang ${ }^{b}$ \\ a Department of Bioenvironmental Systems Engineering, National Taiwan University, Taipei 106, Taiwan, ROC \\ ${ }^{\mathrm{b}}$ Department of Landscape Architecture and Environmental Planning, UC Berkeley, USA
}

\section{A R T I C L E I N F O}

Article history:

Received 18 September 2006

Received in revised form

2 September 2007

Accepted 3 September 2007

Keywords:

Ecological engineering

Lakeshores

Chirixalus idiootocus

Bank substrate

\begin{abstract}
A B S T R A C T
Ecological engineering is the design of sustainable systems, consistent with ecological principles, which integrate human society with its natural environment for the benefit of both. In 2001, the government of Taiwan began to use ecological engineering as a therapy to nurse the damaged environment and found it worthwhile for further promotion for Taiwan's ecological environment. In recent years, the threat to amphibian animals is becoming more and more serious. The problem that concrete is mostly applied as a construction material on lakeshores in Taiwan has resulted in the obvious decrease of the habitats on which amphibian animals rely; hence, the need to develop the relevant design specification considering protecting the amphibian is imperative. Chirixalus idiootocus, an endemic species in Taiwan, is a small brown tree frog widely distributed in altitude ranging under $1500 \mathrm{~m}$ [Chen, W.S., 2003. 31 Frogs in Taiwan. Wild Bird Society of Taipei, pp. 62-63 (in Chinese)] with its unique breeding habitat [Kuramoto, M., Wang, C.S., 1987. A new Rhacophorid Treefrog from Taiwan, with comparisons to Chirixalus eiffingeri (Anura, Rhacophoridae). Copeia 4, 931-942]. Since its uniqueness and importance, it has been a good indicator to reflect the environmental change. However, the understanding of this species is still too little and the methods to protect them have not been developed yet. The goal of this study was to understand the impacts of different substrates, gradients, and humidities of lakebank slopes on the activity of Chirixalus idiootocus. Experiments were carried out on the samplings collected in the field at Chang-Pi Lake. Among the experimental results obtained in this study, the ability of jump height and jump length were $12.93-14.03 \mathrm{~cm}$ and $38.15-39.19 \mathrm{~cm}$, respectively. The male group $\left(\sigma^{7}\right)$ showed the best adhesive ability on awn grass $\left(5.11 \times 10^{-2} \mathrm{~N} / \mathrm{g}\right)$ at $45^{\circ}$ slope, and the () group performed the worst on sand $\left(0.43 \times 10^{-2} \mathrm{~N} / \mathrm{g}\right)$ at $75^{\circ}$ slope. Female frogs showed significant worse performance than male in jump height, jump length, and adhesive abilities, so were considered a target reference to design bank slopes based on their vulnerable behavioral capacity. With better comprehensive results obtained in this study, suggestions for the bank slope designs were thus proposed as a useful reference for ecological engineering promotion in Taiwan.
\end{abstract}

C 2007 Elsevier B.V. All rights reserved.

\section{Introduction}

The emerging discipline of ecological engineering is a response to the growing need for engineering practices to provide for human welfare while at the same time protecting the natural environment from which goods and services are drawn (Bergen et al., 2001). It recognizes that humanity is inseparable from and dependent on natural systems,

* Corresponding author. Tel.: +886 23366 3841; fax: +886 223633275.

E-mail address: f89622050@ntu.edu.tw (Y.-H. Chang).

0925-8574/\$ - see front matter @ 2007 Elsevier B.V. All rights reserved. doi:10.1016/j.ecoleng.2007.09.004 
and that the growing worldwide population and consumption have damaged, and will increasingly stress, global ecosystems (Bergen et al., 1997). Ecological engineering is the design of sustainable systems, consistent with ecological principles, which integrate human society with its natural environment for the benefit of both (Mitsch and Jørgensen, 1989; Mitsch, 1996).

In 2001, the Taiwanese government began to use ecological engineering as a therapy to nurse the damaged environment and promote the innovative methods. Wu and Feng, 2006 proposed that ecological engineering methods are very suitable in mitigation and worthwhile for further promotion for Taiwan's ecological environment. Due to the special environment of Taiwan, the promotion and application of the ecological engineering methods are more difficult than other countries. People of many backgrounds seek localized ecological engineering methods complying with the special geological, hydrological, and environmental conditions of Taiwan to manage the environment for beneficial purposes.

Chirixalus idiootocus, in the family Rhacophoridae, is a small brown tree frog with a brown back and stripes on it. Because of its high similarity with $C$. eiffingeri, it was not identified as a new species until 1987. Specific name idiootocus is a Latinized noun from Greek with 'idios' meaning peculiar and 'ootocus' meaning egg-laying, based on its unique breeding habit (Kuramoto and Wang, 1987). Widely distributed in altitude ranging under $1500 \mathrm{~m}$ (Chen, 2003), C. idiootocus is an endemic species in Taiwan (Taiwan Endemic Species Research Center (TESRC), 1996). Breeding occurs mostly in spring and summer. Males usually call on the ground or among low shrubs near breeding sites, and the predominant calls consist of a series of pulses (Chang, 1989). Differing from all the other frogs, it lays eggs covered with transparent gelatinous coats directly on land near the edge of water or in depressions where water accumulates by rainfall without forming a foam nest. Hatching is apparently stimulated by rain, and hatched tadpoles spend a typical aquatic larval life in ponds or rain pools (Kuramoto and Wang, 1987). Because of its uniqueness, C. idiootocus has been a good indicator of environmental change.

In Taiwan, the amphibian animal has long played an important role with its special ecosystem (Lue, 1996). Due to the need to live on water and land, the quality of the interface area is crucial to their living. In recent years, the threat to amphibian animals is becoming more and more serious. Researchers in different countries have been trying to figure out the problems of decreasing amphibian animals and seek the management methods to restore their habitats (Laurance, 1996; Hamer et al., 2002; Emerson and Diehl, 1980). Others have focused on the sticking ability of frogs under different experimental design and showed that changes of air temperature and humidity have direct effects on the activity levels of frogs (Green and Carson, 1988; Gillespie, 2002; Green, 1981; Hanna and Barnes, 1991). However, in Taiwan, the problem that concrete is mostly applied as a construction material on lakeshores has resulted in the obvious decrease of the habitats on which amphibian animals rely (Hou and Chang, 2004), but no relevant design specification of ecological engineering for protecting the amphibian in Taiwan has been developed yet. Furthermore, no study has been done on how local cli- mate and lakeshore bank conditions may affect the activities of frogs.

The goal of this study was to understand the impacts of different substrates, gradients, and humidities of lakebank slopes on the activity of $C$. idiootocus. Experiments were carried out on the samplings collected in the field and the climate situation at Chang-Pi Lake was simulated. By determining the relationships between experimental factors and the activity of C. idiootocus, a better comprehension may be achieved. Suggestions on the bank slope designs were thus proposed as a useful reference for ecological engineering promotion in Taiwan.

\section{Materials and methods}

\subsection{Study area}

Chang-Pi Lake $\left(21^{\circ} 36^{\prime} 00^{\prime \prime}-121^{\circ} 36^{\prime} 30^{\prime \prime} \mathrm{S}, 24^{\circ} 38^{\prime} 30^{\prime \prime}-24^{\circ} 39^{\prime} 00^{\prime \prime} \mathrm{E}\right)$ is located in Yilan County, northeastern Taiwan (Fig. 1). The average monthly temperature in this area is highest as $32.6^{\circ} \mathrm{C}$ in July and lowest as $13.4^{\circ} \mathrm{C}$ in January. The temperature in spring and autumn ranges between 18.2 and $26.2^{\circ} \mathrm{C}$. The highest average relative humidity is $86 \%$ in May, October, and November and lowest at $81 \%$ in July. The highest average monthly precipitation was $442.3 \mathrm{~mm}$ in October and lowest at $132.2 \mathrm{~mm}$ in March.

\subsection{Sampling}

The samples of C. idiootocus from the Chang-Pi Lake bank were collected in April 2005. Fifty-six male and 16 female frogs were collected in total. Since the frog's behavioral capacity might be affected after long-term raising (Yu, 1976; Lue, 1996), the subsequent laboratory experiments were done within 14 days after the capture. All the creatures were then returned to the original site after the experiments were completed.

\subsection{Experiments}

This study focused on how climate might affect the activity of C. idiootocus with different types of substrates, variable gradients and surface humidities through laboratory experiments.

Eight different substrates, i.e. pebbles, wood (Philippine Mahogony), sand, awn grass (Miscanthus floridulus), clay, brick, steel, and concrete, and seven different slope gradients, namely, $0^{\circ}, 15^{\circ}, 30^{\circ}, 45^{\circ}, 60^{\circ}, 75^{\circ}$, and $90^{\circ}$, were chosen for the experiments to measure the sticking ability per unit body weight. Compared with field findings, information about the eight chosen substrate materials and their relationships with C. idiootocus were describes in Table 1.

According to the historical meteorological records, the weather in Yilan area is mild and humid in spring and autumn because of high precipitation while hot and dry in summer and cold and dry in winter. Both the air temperature and surface moisture of lakeshore bank can thus be categorized to three levels and the combinations of the different levels were used to represent the climate conditions in different seasons in this area. The experimental design is shown in Table 2. A room of constant temperature $3.89 \mathrm{~m}$ long and $1.9 \mathrm{~m}$ wide was 


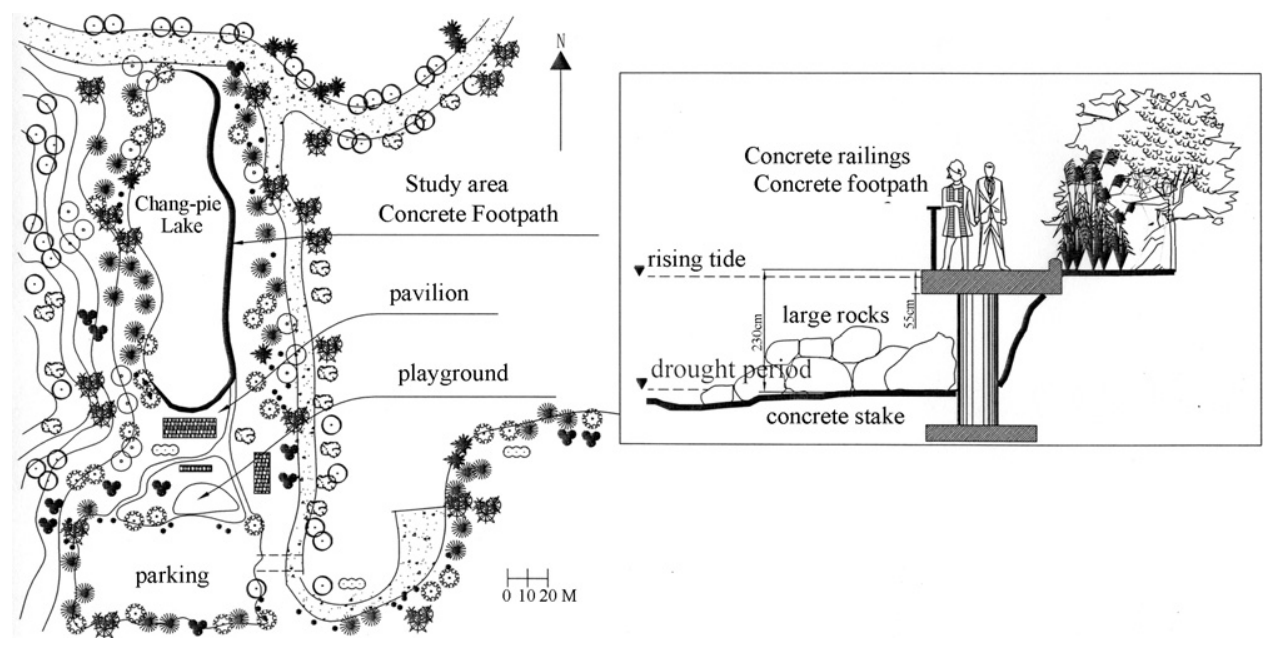

Fig. 1 - The trend of applying concrete on the lakeshores has become a serious problem in the ecological system.

created for environment control purposes. A light source of halogen light bulbs (500 W, $2 \mathrm{~A}$, and $220 \mathrm{~V}$ ) without infrared reflection film was used to simulate the sun, and the temperature was set at a summer temperature of $32^{\circ} \mathrm{C}$, and $14^{\circ} \mathrm{C}$ in winter was simulated using the 'doors and windows insulation method' (China National Standard CNS10523, 1987) with air conditioning and ice cubes. Temperatures of spring and autumn were fixed at $25^{\circ} \mathrm{C}$ via air conditioners. Three levels of humidity conditions, i.e. completely dry (with a surface

Table 1 - Information about the substrate materials

\begin{tabular}{|c|c|}
\hline Material & Descriptions \\
\hline $\begin{array}{l}\text { Awn grass (Miscanthus } \\
\text { floridulus) }\end{array}$ & $\begin{array}{l}\text { 1. Egg masses were often concealed under } \\
\text { fallen leaves (Kuramoto and Wang, 1987) } \\
\text { 2. Vegetation provides shelters for } \\
\text { breeding (Chen, 2003) } \\
\text { 3. Bushes are the most important habitat } \\
\text { (Chen, 2003, Lue) } \\
\text { 4. Only rain pools surrounded by high } \\
\text { grasses or bushes were selected by C. } \\
\text { Idiootocus for breeding (Kuramoto and } \\
\text { Wang, 1987) } \\
\text { 5. During courtship, male frogs were } \\
\text { mostly found to call by dense awn grass }\end{array}$ \\
\hline $\begin{array}{l}\text { Wood (Philippine } \\
\text { Mahogony) }\end{array}$ & $\begin{array}{l}\text { 1. Egg masses were often concealed under } \\
\text { fallen branches (Kuramoto and Wang, } \\
\text { 1987) } \\
\text { 2. Rotten wood provides the habitat for } \\
\text { insects which are one of the food sources } \\
\text { to C. Idiootocus }\end{array}$ \\
\hline Pebble & $\begin{array}{l}\text { 1. Egg masses were often concealed under } \\
\text { pebbles (Kuramoto and Wang, 1987) } \\
\text { 2. Pebble caves provide shelters from } \\
\text { invaders }\end{array}$ \\
\hline Sand, clay & $\begin{array}{l}\text { Minute soil granules attached on the outer } \\
\text { surface of the jelly coat }\end{array}$ \\
\hline $\begin{array}{l}\text { Brick, steel, and } \\
\text { concrete }\end{array}$ & $\begin{array}{l}\text { Artificial material, as a contrast to natural } \\
\text { material }\end{array}$ \\
\hline
\end{tabular}

humidity of $0 \%$ ), semi-moist (with a surface humidity of $50 \%$ ), and completely wet (with a surface humidity of $100 \%$ ), were created to understand how the surface humidity influence the adhesive ability of frogs. For surface with $0 \%$ humidity, the substrate was used after being wiped to dry and placed in an electronic dryer set at constant temperature $25^{\circ} \mathrm{C}$ for $24 \mathrm{~h}$. For substrates with $100 \%$ humidity, a sprayer was used to apply water onto the surface until it was saturated. For semimoist condition, the substrates with $100 \%$ humidity were placed in an environment with a relative humidity of $65-70 \%$ under three different temperature regimes of 32,25 , and $14{ }^{\circ} \mathrm{C}$. After evaporating for $5 \mathrm{~min}$, the experiment could then be proceeded.

An electronic scale and a vernier caliper were used to measure the frogs' body weights and straight body lengths, respectively. The toe pad surface area was calculated by using CAD software (Lee et al., 2001) according to the scanned drawing caught by an electron microscope. For the behavioral capacity measurement, jumping distance and jumping height were recorded (Cadiergues et al., 2000). The specimen was placed at a fixed position on a $100 \mathrm{~cm} \times 100 \mathrm{~cm}$ flat board first, and the mean distance of five long jumps was measured then. For jumping height measurement, 5-cm-diameter paper tubes reeled from $1 \mathrm{~mm}$ thick cardboard, with heights ranging from 5 to $20 \mathrm{~cm}$ was used. The height difference between each paper tube was $1 \mathrm{~cm}$. With grass as a stimulus, five jumps with 1-min interval were surveyed and the average was calculated.

The stickiness of the treefrogs was tested using a simple apparatus (Green, 1981; Fig. 2). Each frog was swathed in wet cloth and fastened to an electronic spring scale by a cotton string. The string and the scale were kept parallel to the substrate surface. By pulling the scale gradually with an interval of $1 \mathrm{~min}$ in-between, the adhesive ability could thus be measured. The unit of measurement was $\mathrm{N}\left(\mathrm{kgm} / \mathrm{s}^{2}\right)$, and the mean value and standard deviation of five jumps were calculated. Each set of simulations had to be completed within $10 \mathrm{~min}$. During the entire experiment, the tree frogs' skin was kept moist. The upper limits of frogs' adhesive ability within 


\begin{tabular}{l} 
Table 2 - Experimental design for the relationship between bank slope substrate and climatic conditions \\
\cline { 2 - 4 } Humidity
\end{tabular}

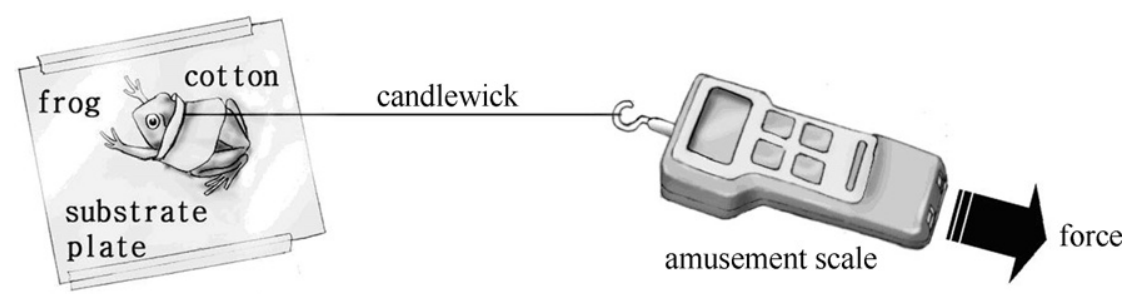

Fig. 2 - The apparatus used in the study to measure the sticking ability of the frog's four limbs.

different groups were then discussed to find the optimal substrate and bank slope designs suitable for frog habitat.

\subsection{Statistical analysis}

Eight substrate materials and seven gradients of bank slope under different climate situations were studied in this experiment. Repeated measurement data of adhesive ability was obtained on testing each frog. With its repeated measurement design of this study, the dependency of data within frog was considered and the repeated measurement analysis of variance (ANOVA) method was hence used to test the mean difference of sticking ability on different substrate material and gradients.

\section{Results and discussions}

\subsection{Body and behavioral capacity measurements}

Since the samplings were done during the female frogs' pregnancy period, the average body weight and length of female frogs were measured $1.78 \mathrm{~g}$ and $1.1 \mathrm{~cm}$ heavier and longer than those of male frogs. The mean area of the four toe pads was $1.05 \pm 0.09 \mathrm{~cm}^{2}$ for males, and $1.38 \pm 0.05 \mathrm{~cm}^{2}$ for females. Significant differences between genders were revealed in weight, body length, and toe pad areas, resulting in a notable difference in the jump height, jump length, and adhesive abilities. The male frogs' behavioral capacity was clearly superior to that of female frogs by up to 2.3-2.5-times in magnitude, as shown in Table 3. Since the existing female frogs are one tenth of male (Chang, 1989), considering its importance to the reproduction of the frogs, female frogs (o) with their behavioral capacity were chosen as the target for reference of ecological engineering design on bank slopes.

\subsection{Effects of temperatures on the adhesive ability of C. idiootocus in relation to different substrates and angles}

\subsubsection{Effects of different substrates on the adhesive} ability of different gender groups in spring and autumn The adhesive ability $(\mathrm{N})$ of $\mathrm{C}$. idiootocus was measured on eight different substrates at slopes ranging from $15^{\circ}$ to $75^{\circ}$. By using dimensionless analysis, the adhesive ability per unit weight $(\mathrm{N} / \mathrm{g})$ was obtained as in Fig. 3. As shown in Fig. 3, the male frog's adhesive ability per unit weight was clearly better than that of the female frog. For tests on awn grass at a slope of $75^{\circ}$ as an example, male frogs' adhesive ability was $56 \%$ greater than that of female frogs. In terms of differences between the eight substrates at any slope angle, it was evident that the adhesive ability was the best on awn grass and worst on sand. It could be concluded that awn grass is the best substrate to which frogs could adhere. For the female group (o) on an awn grass slope from $15^{\circ}$ to $75^{\circ}$, the best performance was at $30-45^{\circ}$, and adhesive forces of up to $3.53 \times 10^{-2} \mathrm{~N} / \mathrm{g}$ were recorded. When the slope angle reached $60^{\circ}$, the adhesive ability decreased by $31 \%$ and to $75^{\circ}$ by $59 \%$. Comparing the adhesive ability of the two groups on awn grass, the $\left(\sigma^{7}\right)$ group is superior to (o) group by about $52 \%$. As a whole, male group $\left(\sigma^{\top}\right)$ showed the best adhesive ability on awn grass $\left(5.11 \times 10^{-2} \mathrm{~N} / \mathrm{g}\right)$ at $45^{\circ}$ slope, and the (ㅇ) group performed the worst on sand $\left(0.43 \times 10^{-2} \mathrm{~N} / \mathrm{g}\right)$ at $75^{\circ}$ slope.

\subsubsection{Adhesive ability of female frogs with different} substrates and different surface temperatures at slope $60^{\circ}$ The relationship between the surface temperature and the frogs' adhesive ability is shown in Table 4 . At $60^{\circ}$ slope in summer, the performances of female frogs' adhesive ability were $48 \%, 67 \%, 2 \%, 34 \%, 18 \%, 57 \%$, and $23 \%$ on wood, pebbles, sand, clay, steel, brick, and concrete, respectively while $100 \%$ was set on awn grass. It seems no consistent positive 
Table 3 - Physical measurements and their relationships with behavioral capacities

\begin{tabular}{|c|c|c|c|c|c|c|c|c|c|c|}
\hline \multirow[t]{2}{*}{ Classification } & \multirow{2}{*}{$\begin{array}{l}\text { No. of } \\
\text { samples }\end{array}$} & \multicolumn{3}{|c|}{ Physical measurement } & \multicolumn{2}{|c|}{ Behavioral } & \multicolumn{4}{|c|}{ Behavioral capacity correlations } \\
\hline & & [1], weight (g) & $\begin{array}{l}\text { [2], length } \\
(\mathrm{cm})\end{array}$ & $\begin{array}{l}\text { [3], toe pad surface } \\
\text { area }\left(\mathrm{cm}^{2}\right)\end{array}$ & $\begin{array}{l}\text { [4], high } \\
\text { jump }(\mathrm{cm})\end{array}$ & $\begin{array}{l}\text { [5], long jump } \\
(\mathrm{cm})\end{array}$ & $\begin{array}{c}{[6],[4] /[1]} \\
(\mathrm{cm} / \mathrm{g})\end{array}$ & $\begin{array}{c}{[7],[5] /[1]} \\
(\mathrm{cm} / \mathrm{g})\end{array}$ & $\begin{array}{l}{[8],[4] /[3]} \\
\left(\mathrm{cm} / \mathrm{cm}^{2}\right)\end{array}$ & $\begin{array}{l}{[9],[5] /[3]} \\
\left(\mathrm{cm} / \mathrm{cm}^{2}\right)\end{array}$ \\
\hline f & 56 & $1.29 \pm 0.13$ & $2.96 \pm 0.09$ & $1.05 \pm 0.09$ & $14.03 \pm 3.12$ & $38.15 \pm 6.60$ & $10.89 \pm 2.47$ & $29.65 \pm 5.10$ & $13.37 \pm 3.06$ & $36.32 \pm 6.14$ \\
\hline
\end{tabular}

Significant differences between genders were shown in weight, body length, and toe pad areas, and jump height and length as well.

Table 4 - Adhesive ability $\left(\times 10^{-2} \mathrm{~N} / \mathrm{g}\right)$ of female frogs in different seasons and on different slope substrates

\begin{tabular}{|c|c|c|c|c|c|c|c|c|c|}
\hline Items & Season & Awn grass & Wood & Pebbles & Sand & Clay & Steel & Brick & Concrete \\
\hline \multirow{3}{*}{ Season } & Winter $\left(14^{\circ} \mathrm{C}\right)$ & $3.83 \pm 0.30$ & $2.35 \pm 0.31$ & $3.89 \pm 0.70$ & $0.32 \pm 0.09$ & $1.71 \pm 0.33$ & $1.09 \pm 0.25$ & $2.22 \pm 0.08$ & $1.37 \pm 0.29$ \\
\hline & Spring \& autumn $\left(25^{\circ} \mathrm{C}\right)$ & $2.44 \pm 0.73$ & $1.07 \pm 0.12$ & $1.06 \pm 0.13$ & $0.43 \pm 0.04$ & $1.08 \pm 0.11$ & $1.12 \pm 0.13$ & $1.02 \pm 0.16$ & $1.10 \pm 0.20$ \\
\hline & Summer $\left(32^{\circ} \mathrm{C}\right)$ & $4.26 \pm 0.40$ & $2.04 \pm 0.27$ & $2.84 \pm .0 .55$ & $0.10 \pm 0.02$ & $1.46 \pm 0.21$ & $0.75 \pm 0.24$ & $2.41 \pm 0.38$ & $0.98 \pm 0.29$ \\
\hline
\end{tabular}




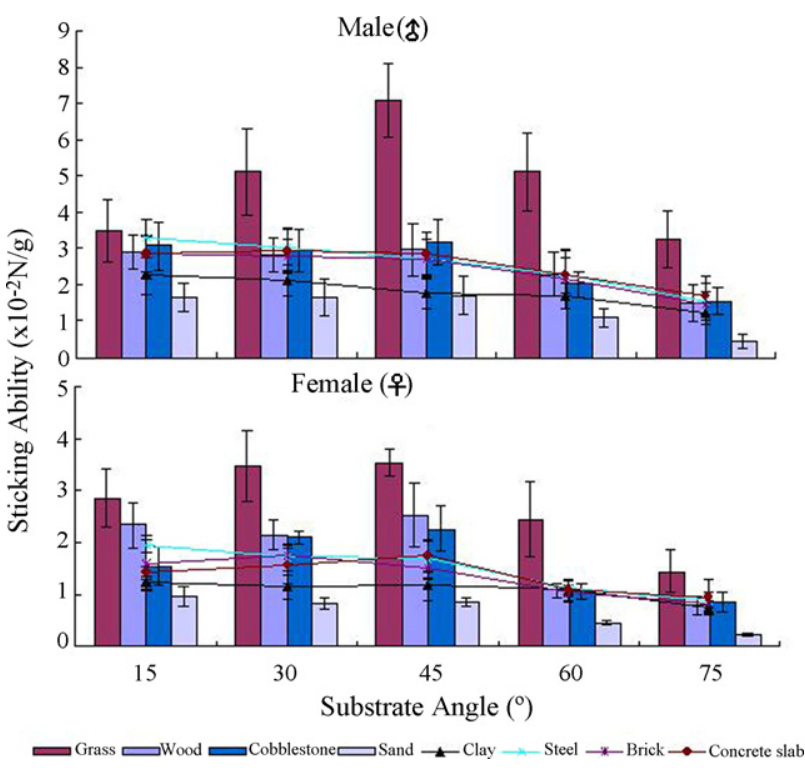

Fig. 3 - Adhesive ability of the two groups on slopes of different substrates at angles ranging from $15^{\circ}$ to $75^{\circ}$. As a whole, male group performed the best at $45^{\circ}$ on awn grass while the female group showed the worst at $75^{\circ}$ on sand. Note: the environmental condition was a simulation of spring and autumn in Ilan. Air temperature: $25^{\circ} \mathrm{C}$; substrate surface humidity: $100 \%$.

or negative correlations between the two factors. The ability to adhere to steel was decreasing by up to $33 \%$ in summer. For awn grass, wood, and pebbles, the adhesive abilities in spring and autumn were the worst, which might influence the reproduction of frogs. Hence, conditions in spring and autumn (medium temperature) were discussed more in the following.

\subsection{Effects of surface humidity of different substrates} on female frogs' adhesive ability

\subsubsection{Adhesive ability of female $C$. idiootocus on different} substrates and humidities at bank slope $60^{\circ}$ in spring and autumn

As shown in Table 5, the humidity level was negatively correlated to the frog's adhesive ability on awn grass, wood, pebbles, and clay. For awn grass as an example, the adhesive ability on a dry surface was $35 \%$ better than that on a semi-humid surface; and that on a semi-humid surface was $38 \%$ better than that on a saturated surface. As for the other four types of substrates (sand, steel, brick, concrete), the best adhesive ability for the female frogs was found in a semi-humid condition. In this table, the adhesive ability on awn grass was set to a value of $100 \%$ as the best performance to compare with those under other substrates and different humidity conditions. Under the low-humidity condition in spring and autumn, the adhesive abilities on wood and pebbles were about two-thirds of that on awn grass. The performances on the other substrates were less than half of that on awn grass. The worst performance was on sand with difference more than $93 \%$. Under conditions of high humidity, the adhesive ability on sand was only $17 \%$ of that on awn grass, while differing from $54 \%$ to $58 \%$ on other substrates.

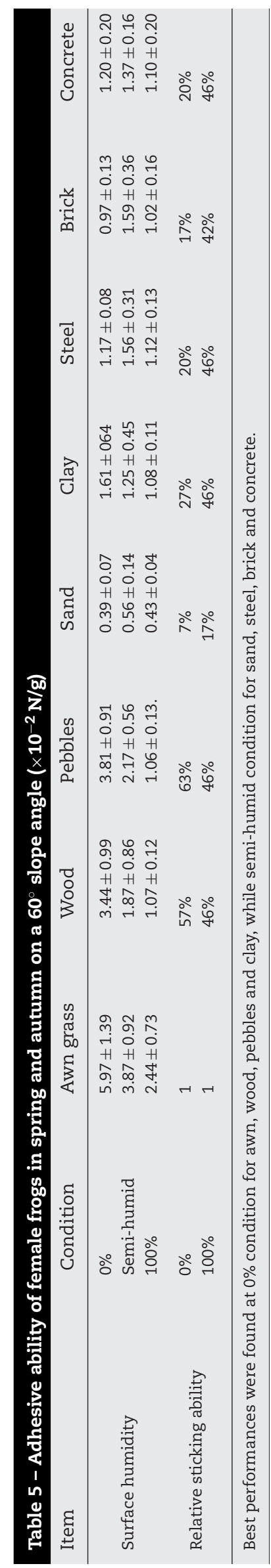


Table 6 - Suggested maximum slope angle for bank design with female frogs as target on three different chosen substrates $\left(\times 10^{-2} \mathrm{~N} / \mathrm{g}\right)$

\begin{tabular}{llccc} 
Rank & Substrate & Max. slope angle & Sticking ability & Climate \\
\hline 1 & Awn grass & $\leqq 75^{\circ}$ & $1.44 \pm 0.42$ & Medium temperature high humidity \\
2 & Pebbles & $\leqq 60^{\circ}$ & $1.06 \pm 0.13$ & Medium temperature high humidity \\
3 & Wood & $\leqq 45^{\circ}$ & $1.38 \pm 0.31$ & Low temperature low humidity \\
\hline
\end{tabular}

Table 7 - Means of sticking ability by substrate material

\begin{tabular}{lcccc} 
Substrate material & Mean & Std. error & \multicolumn{2}{c}{$95 \%$ confidence interval } \\
\cline { 3 - 5 } & & & Lower bound & Upper bound \\
\hline Grass & 5.740 & 0.042 & 5.650 & 5.830 \\
Wood & 3.703 & 0.026 & 3.280 & 3.759 \\
Cobblestone & 3.346 & 0.031 & 0.343 & 3.412 \\
Sand & 0.367 & 0.012 & 1.496 & 1.150 \\
Clay & 1.521 & 0.012 & 2.966 & 1.547 \\
Steel & 1.179 & 0.014 & 1.820 & 3.106 \\
Brick & 3.036 & 0.033 & 012 & 1.871 \\
Concrete slab & 1.846 & 0.012 & & \\
\hline
\end{tabular}

This indicated that the adhesive ability of frogs was influenced by the different substrates and different humidity levels.

\subsubsection{Comparisons among different slope angles and} humidities on awn grass and concrete

As the results in Fig. 4 suggested, the surface substrate of awn grass would consistently give a better performance compared to that of concrete surface regardless of the humidity level. At a $60^{\circ}$ slope, the performance on awn grass was $80 \%$ better than that on concrete when dry, and $65 \%$ and $55 \%$ better in the semi-humid and saturated condition, respectively.

\subsection{The bank slope designs}

The design of banks should include considerations of species with inferior existence and high vulnerability. We chose female frogs as the target for bank design because of their inferior quality on adhesive ability according to our findings. The three types of natural substrates, i.e. awn grass, wood, and pebbles, were chosen and the suggested slopes were no greater than $75^{\circ}$ for awn grass, $60^{\circ}$ for pebbles, and $45^{\circ}$ for wood. The experimental results are shown in Table 6.

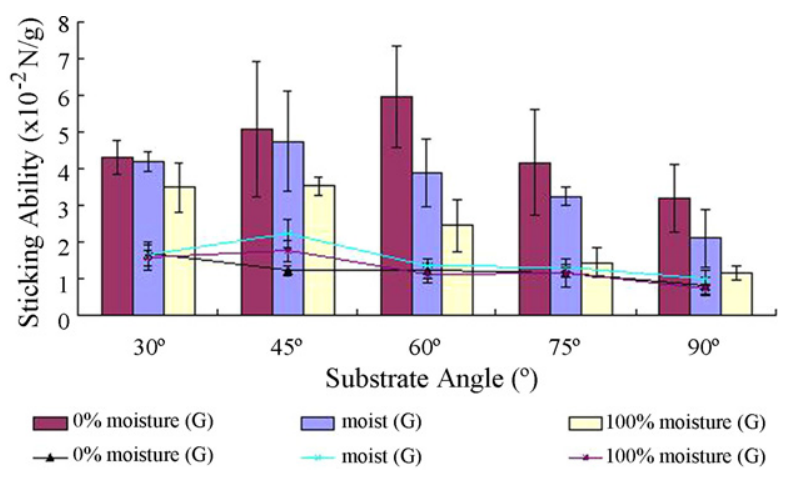

Fig. 4 - Adhesive ability of female frogs on awn grass and concrete under different humidity levels in the spring and autumn (at $25^{\circ} \mathrm{C}$ ) condition. G: awn grass; C: concrete.
Table 8 - Means of sticking ability by slope gradients

\begin{tabular}{rcccc} 
Angle & Mean & Std. error & \multicolumn{2}{c}{ 95\% confidence interval } \\
\cline { 3 - 5 } & & & Lower bound & Upper bound \\
\hline 0 & 3.655 & 0.020 & 3.612 & 3.698 \\
15 & 3.387 & 0.020 & 3.343 & 3.430 \\
30 & 3.126 & 0.024 & 3.075 & 3.176 \\
45 & 2.835 & 0.023 & 2.786 & 2.884 \\
60 & 2.140 & 0.016 & 2.106 & 2.175 \\
75 & 1.651 & 0.021 & 1.606 & 1.697 \\
90 & 1.353 & 0.020 & 1.310 & 1.396 \\
\hline
\end{tabular}

\subsection{Hypothesis test results}

By the repeated measurement ANOVA, the main effect of substrate material and gradient on frog's sticking ability are all significant $(p<0.001)$ (Tables 7 and 8). The all pair-wise comparisons of estimated mean sticking ability on 8 substrate materials and 7 gradients are also significant $(p<0.001)$ with least significant difference (LSD) adjustment for multiple comparisons. Grass has the highest sticking ability with estimated mean sticking ability as 5.74 and $95 \%$ confidence interval (C.I.) 5.650-5.830, while sand has the lowest with estimated mean sticking ability as 0.367 and $95 \%$ confidence interval (C.I.) $0.343-0.392$. The estimated mean sticking ability for overall 8 substrate materials at angle $0^{\circ}$ is 3.655 with $95 \%$ C.I. as 3.612-3.698 and 1.353 with $95 \%$ C.I. as $1.310-1.396$ at angle $90^{\circ}$. As indicated in Fig. 5, the increase of gradient will decrease frog's sticking ability no matter what the substrate material is.

\section{Conclusions}

Ecological engineering in Taiwan is not yet mature yet and still in the process with continuous efforts and inputs for further promotion to protect the unique environment resources on the island. 


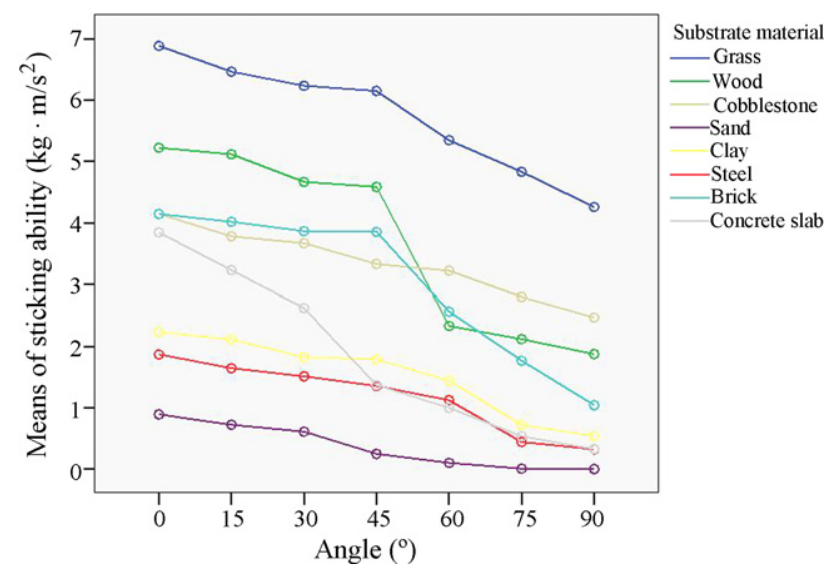

Fig. 5 - Means of sticking ability by gradients and substrate material. It is obvious that the increase of gradient will decrease frogs' sticking ability regardless of the substrate material.

In the present study, experiments have been done under different designed conditions to examine the activity of the Taiwanese endemic species, C. idiootocus, collected from Chang-Pi Lake bank in Yilan. Among the experimental results obtained in this study, the ability of jump height and jump length were $12.93-14.03 \mathrm{~cm}$ and $38.15-39.19 \mathrm{~cm}$, respectively. Male group $\left(0^{7}\right)$ showed the best adhesive ability on awn grass $\left(5.11 \times 10^{-2} \mathrm{~N} / \mathrm{g}\right)$ at $45^{\circ}$ slope, and the (o) group performed the worst on sand $\left(0.43 \times 10^{-2} \mathrm{~N} / \mathrm{g}\right)$ at $75^{\circ}$ slope. Female frogs showed significant worse performance than male in jump height, jump length, and adhesive abilities, so were considered as a target reference to design bank slopes based on their vulnerable behavioral capacity. The results were found to be valuable for ecological engineering on lakeshores.

As the experimental data indicated, adhesive ability was the best on awn grass and worst on sand. It could be concluded that awn grass is the best substrate to which frogs could adhere. Half of Chang-Pi Lake's bank shore is now made of concrete. Modification by planting is strongly suggested to improve the habitat for $C$. idiootocus, especially during their reproductive season. The guideline of designing according to the local environment and using locally available material whenever possible in applying ecological engineering should be followed (Kuo, 2006). The three types of natural substrates, i.e. awn grass, wood, and pebbles, were chosen as suitable materials and the suggested slopes were no greater than $75^{\circ}$ for awn grass, $60^{\circ}$ for pebbles, and $45^{\circ}$ for wood. The use of these different materials could work in coordination and hold uniformity to minimum to preserve as much natural habitat as possible, and more emphasis and maintenance on replacement of vegetative cover and bank vegetation could improve habitat by minimizing erosion problems as well.

There is clear evidence that the substrates and weather conditions played a significant role in the activity of $C$. idiootocus. The use of materials is critical for the survival and growth of this species because of its unique breeding behavior. In conclusion, our data could be provided to guide ecological engineers to select corresponding strategies and assist with priority settings. We believe that experiments should be con- tinued and that a larger sample of bank sites would strengthen the results found in this study.

\section{REFERENCES}

Bergen, S.D., Bolton, S.M., Fridley, J.L., 1997. Ecological engineering: design based on ecological principles. Presented at the 1997 ASAE Annual International Meeting. Paper No. 975035. ASAE, 2950 Niles Rd., St. Joseph, MI 49085-9659, USA.

Bergen, S.D., Bolton, S.M., Fridley, J.L., 2001. Design principles for ecological engineering. Ecol. Eng. 18, 201-210.

Cadiergues, M.C., Joubert, C., Frane, M., 2000. A comparison of jump performances of the dog flea, Ctenocephalides canis (Curtis, 1826) and the cat flea, Ctenocephalides felis (Bouche, 1835). Vet. Parasitol. 92, 239-241.

Chang, Y.W., 1989. The Reproductive Behavior of Chirixalus idiootocus. Master's Thesis. Science Graduate Institute, Zoology, National Taiwan University, Taipei, Taiwan, pp. 12-54.

Chen, W.S., 2003. 31 Frogs in Taiwan. Wild Bird Society of Taipei, pp. 62-63 (in Chinese).

Emerson, S.B., Diehl, D., 1980. Toe pad morphology and mechanisms of sticking in frogs. J. Linn. Soc. 13, 199-216.

Gillespie, G.R., 2002. Impacts of sediment loads, tadpole density, and food type on the growth and development of tadpoles of the spotted tree frog. Biol. Conserv. 106, 141-150.

Green, D.M., 1981. Adhesion and toe-pads of tree frogs. Copeia 4, 790-796.

Green, D.M., Carson, J., 1988. The adhesion of tree frog toe-pads to glass: cryogenic examination of a capillary adhesion system. J. Nat. Hist. 22, 131-135.

Hamer, A.J., Lane, S.J., Mahony, M.J., 2002. Management of freshwater wetlands for the endangered green and golden bell frog (Litoria aurea): roles of habitat determinants and space. Biol. Conserv. 106, 413-424.

Hanna, G., Barnes, W.J., 1991. Adhesion and detachment of the toe pads of tree frogs. J. Exp. Biol. 155, 103-125.

Kuo, C.C., 2006. Using ecotechnology to redirect Taiwan's construction work away from conventional method. Ecol. Eng. 28, 325-332.

Kuramoto, M., Wang, C.S., 1987. A new Rhacophorid Treefrog from Taiwan, with comparisons to Chirixalus eiffingeri (Anura, Rhacophoridae). Copeia 4, 931-942.

Laurance, W.F., 1996. Catastrophic declines of Australian rainforest frogs is unusual weather responsible. Biol. Conserv. 77, 203-212.

Lee, W.J., Lue, K.Y., Lue, C.H., 2001. The SEM comparative study on toe among 19 species of tree frogs from Taiwan. BioFormosa $36,27-36$.

Lue, K.Y., 1996. A Handbook of Amphibian Animal Resources. Council of Agriculture, Executive Yuan, R.O.C, pp. 31-33 (in Chinese).

Mitsch, W.J., 1996. Ecological engineering: a new paradigm for engineers and ecologists. In: Schulze, P.C. (Ed.), Engineering within Ecological Constraints. National Academy Press, Washington, DC, pp. 114-132.

Mitsch, W.J., Jørgensen, S.E., 1989. Introduction to ecological engineering. In: Mitsch, W.J., Jørgensen, S.E. (Eds.), Ecological Engineering: An Introduction to Ecotechnology. Wiley, New York, pp. 3-12.

Taiwan Endemic Species Research Center (TESRC), 1996. Taiwanese Endemic Species. Taiwan Endemic Species Research Center, Nantou, Taiwan (in Chinese).

Wu, H.L., Feng, Z.Y., 2006. Ecological engineering methods for soil and water conservation in Taiwan. Ecol. Eng. 28, 333-344.

Yu, W.C., 1976. Biometrics with Experiment Designs. Nung-Ying Books, pp. 234-262. 